ÉESTI NSV TEADUSTE AKADEEMIA TOIMETISED. GEOLOOGIA

ИЗВЕСТИЯ АКАДЕМИИ НАУК ЭСТОНСКОИ ССР. ГЕОЛОГИЯ

PROCEEDINGS OF THE ACADEMY OF SCIENCES OF THE ESTONIAN SSR. GEOLOGY

$1986,35,2$

УДК $552.124 .3(474.2)$

В. КЛЕНН, Маре КОНСА

\title{
РАСПРЕДЕЛЕНИЕ АКЦЕССОРНЫХ МИНЕРАЛОВ В МЕТАМОРФИЧЕСКИХ КОМПЛЕКСАХ НИЖНЕГО ПРОТЕРОЗОЯ СЕВЕРНОЙ ЭСТОНИИ
}

Кристаллический фундамент Эстонии сложен преимущественно метаморфическими породами, причем акцессорные минералы до сих пор специально не изучались. Исследование акцессорных минералов представляет интерес с точки зрения решения многих геологических вопросов, в частности: 1) расчленения комплексов пород, 2) определения их исходной природы, 3) оценки их рудной специализации, 4) выяснения источников сноса при формировании базальных слоев осадочного чехла (Конса, Вийдинг, 1983).

Настоящее сообщение является первым кратким обзором о распространении наиболее часто встречающихся акцессорных минералов в главных типах нижнепротерозойских метаморфитов Северной Эстонии. Несмотря на ограниченное число изученных разрезов (рисунок) и небольшое количество проб (табл. 1), а также методику, специально разработанную для исследований осадочных пород Прибалтики (Вийдинг, 1976), получены результаты, позволяющие наметить основные закономерности распространения акцессорных минералов в породах разных структурных зон свекофеннского пояса Северной Эстонии.

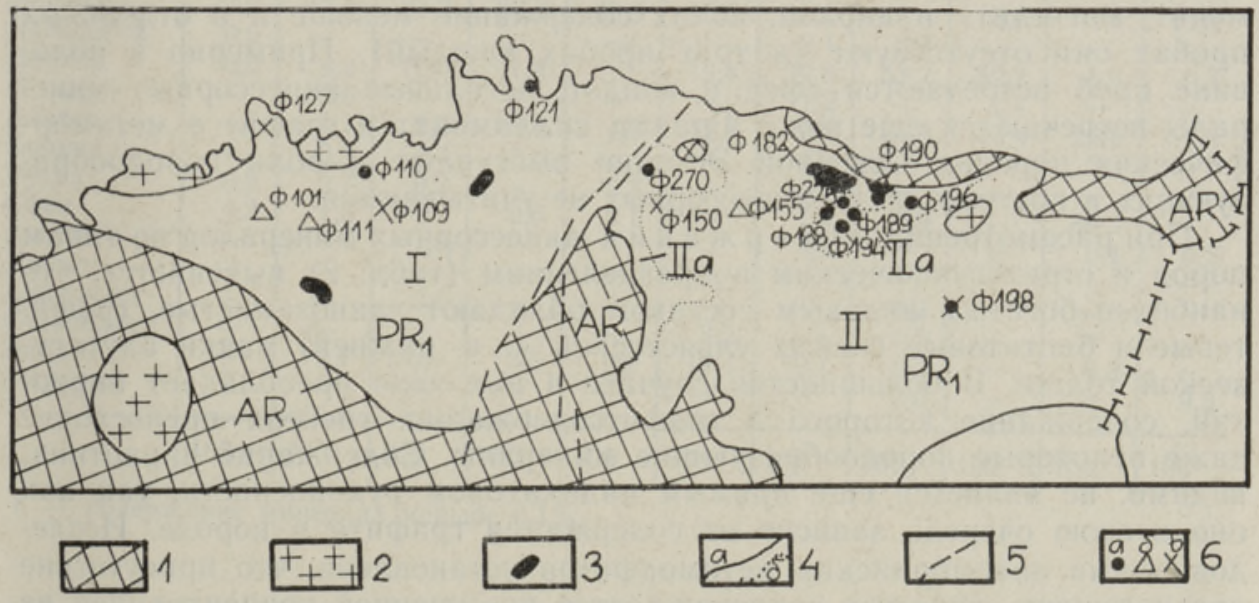

Расположение изученных разрезов в нижнепротерозойских структурных зонах Северной Эстонии с распространением пород ягалаской толши (I) и мяэтагузеской (II) и ульястеской (На) пачек алутагузеской толщи. I - блоки досвекофеннского (архейского) возраста, 2 - массивы порфировидных калиевых гранитов, 3 - массивы габброидов, 4 - геологические границы между разновозрастными комплексами $(a)$ и мяэтагузеской и ульястеской пачками (б), 5 - Тапаская зона разломов, 6 - буровые скважины, с изученными разрезами глиноземистых, графитовых и биотитовых гнейсов $(a)$, кварц-полевошпатовых гнейсов (б), биотит-амфнболовых гнейсов $(8)$. 
Чัастота встречаемости акцессорных

и рудных минералов в типах пород, \%

\begin{tabular}{|c|c|c|c|}
\hline Минерал & $\begin{array}{c}\text { Глиноземистые, } \\
\text { графитовые и био- } \\
\text { титовые гнейсы } \\
(n=12)\end{array}$ & $\begin{array}{c}\text { Кварц-полево- } \\
\text { шпатовые } \\
\text { гнейсы } \\
(n=4)\end{array}$ & $\begin{array}{c}\text { Бнотит- } \\
\text { амфиболовые } \\
\text { гнейсы } \\
(n=5)\end{array}$ \\
\hline $\begin{array}{l}\text { Ильменит + магнетит } \\
\text { Пирит + пирротин } \\
\text { Лейкоксен } \\
\text { Циркон } \\
\text { Монацит } \\
\text { Апатит } \\
\text { Корунд } \\
\text { Рутил } \\
\text { Сфен } \\
\text { Анатаз } \\
\text { Дистен } \\
\text { Андалузит } \\
\text { Ставролит } \\
\text { Эпидот } \\
\text { Флуорит }\end{array}$ & $\begin{array}{r}83 \\
100 \\
17 \\
92 \\
42 \\
100 \\
50 \\
50 \\
50 \\
17 \\
17 \\
8 \\
8 \\
67 \\
\end{array}$ & $\begin{array}{r}100 \\
100 \\
50 \\
100 \\
25 \\
100 \\
- \\
\overline{50} \\
- \\
50 \\
25 \\
50 \\
25\end{array}$ & $\begin{array}{r}80 \\
100 \\
\overline{60} \\
\frac{-}{100} \\
20 \\
\overline{40} \\
40 \\
- \\
\overline{-} \\
20 \\
20\end{array}$ \\
\hline
\end{tabular}

$n+$ количество проб.

Результаты изучения акцессорных минералов рассматриваются на фоне валового минерального состава пород. Подсчет породообразующих минералов в шлифах в основном проводил $M$. Нийн (группа глубинного картирования Управления геологии ЭССР). Авторы искренне признательны ему за предоставление материалов.

По частоте встречаемости (табл. 1) выделяются сульфиды (пирит, пирротин) и апатит. Они встречаются во всех проанализированных пробах, их содержание колеблется в больших пределах. Во всех структурных зонах и типах пород распространены также окислы (ильменит, магнетит) и циркон, но их содержание меньше и в отдельных пробах они отсутствуют (в трех пробах каждый). Примерно в половине проб встречаются сфен и эпидот, остальные акцессорные минералы встречаются еще реже. Гранат, силлиманит и графит в метаморфических породах Северной Әстонии выступают в роли породообразующих и поэтому среди акцессорных не учитываются.

При рассмотрении содер жан и я акцессорных минералов по типам пород и стратиграфическим подразделениям (табл. 2) выясняется, что наиболее богатым видовым составом обладают глиноземистые, графитовые и биотитовые гнейсы ульястеской (т.е. нижней) пачки алутагузеской толщи. В большинстве случаев в них явно преобладает пирротин, содержание которого в графитсодержащих гнейсах превосходит даже некоторые породообразующие минералы. Содержание пирротина, видимо, не является еще прямым индикатором рудоносности, так как оно в свою очередь зависит от содержания графита в породе. Исследованиями докембрийских метаморфитов установлено, что присутствие органогенного вещества сопровождается повышенной концентрацией не только рудных, но и многих других акцессорных минералов (Сидоренко, Ляхович, 1982; Геренчук и др., 1983). Однако анализ наших материалов показывает, что четкой корреляции между содержанием графита и нерудных акцессорных минералов в нижнепротерозойских метаморфитах Эстонии не наблюдается.

В породах ягалаской толщи и мяэтагузеской пачки алутагузеской толщи содержание рудных минералов, среди которых преобладает пир- 
Таблица 2

Содержание породообразующих и акцессорных минералов в метаморфических породах нижнего протерозоя Северной Эстонии (1 - ягалаская толща,

II - мяэтагузеская пачка, IІа - ульястеская пачка), \%

\begin{tabular}{|c|c|c|c|c|c|c|c|c|c|c|c|}
\hline \multirow[t]{2}{*}{ Минералы } & \multicolumn{3}{|c|}{$\begin{array}{c}\text { Глиноземистые } \\
\text { гнейсы }\end{array}$} & \multicolumn{2}{|c|}{$\begin{array}{l}\text { Графитовые } \\
\text { гнейсы }\end{array}$} & \multicolumn{2}{|c|}{$\begin{array}{l}\text { Биотитовые } \\
\text { гнейсы }\end{array}$} & \multicolumn{2}{|c|}{$\begin{array}{c}\text { Кварц-поле- } \\
\text { вошпатовые } \\
\text { гнейсы }\end{array}$} & \multicolumn{2}{|c|}{$\begin{array}{c}\text { Бнотит- } \\
\text { амфибо- } \\
\text { ловые } \\
\text { гнейсы }\end{array}$} \\
\hline & I & II & $\mathrm{IIa}$ & I & IIa & II & IIa & I & II & I & II \\
\hline
\end{tabular}

А. Породообразующие

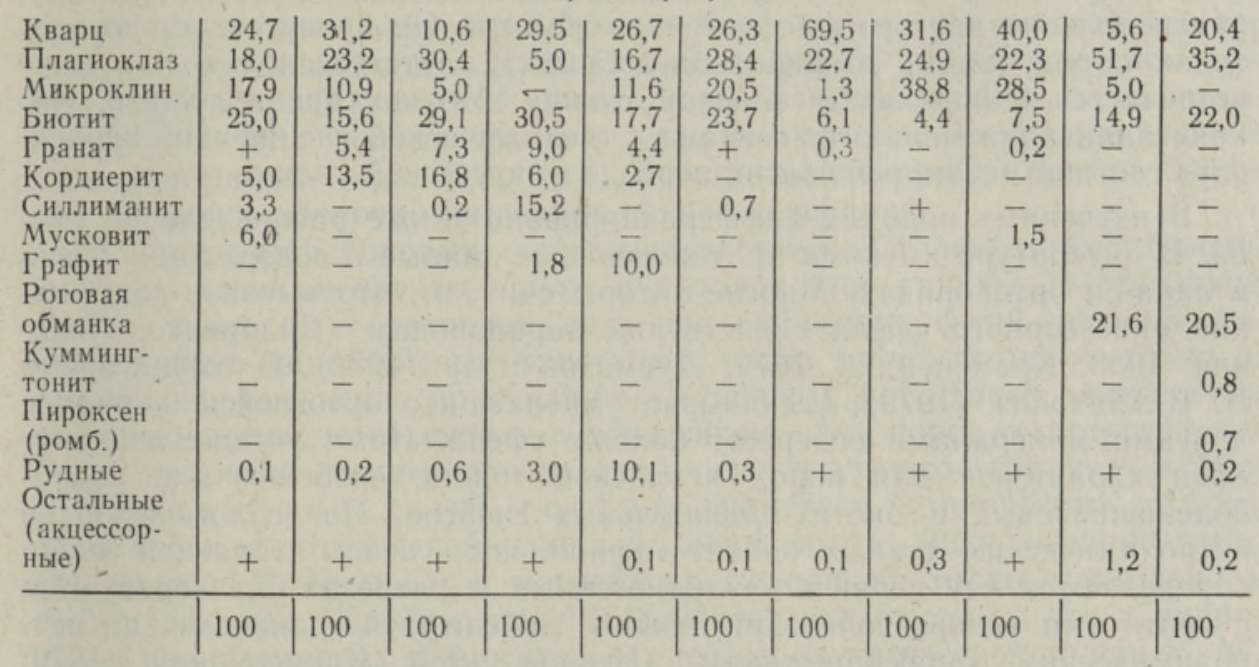

Б. Акцессорные и рудные

\begin{tabular}{|c|c|c|c|c|c|c|c|c|c|c|c|}
\hline $\begin{array}{l}\text { Ильменит + } \\
\text { магнетит } \\
\text { Пирит + }\end{array}$ & 10,3 & 27,3 & 22,7 & 1,7 & 2,6 & 9,7 & 1,4 & 0,9 & 2,4 & 0,2 & 23,2 \\
\hline $\begin{array}{l}\text { пирротин } \\
\text { Лейкоксен }\end{array}$ & 72,9 & 47,6 & 47,7 & 68,2 & 89,9 & 35,5 & 10,5 & 16,6 & 3,6 & 1,0 & 15,8 \\
\hline $\begin{array}{l}\text { Лейкоксен } \\
\text { Циркон }\end{array}$ & $\begin{array}{l}0,5 \\
65\end{array}$ & $\overline{9} .2$ & 100 & $\overline{11.8}$ & $\bar{t}$ & $\overline{19.4}$ & $\begin{array}{r}2,1 \\
398\end{array}$ & $\begin{array}{r}0,6 \\
5\end{array}$ & 822 & 5,3 & 07 \\
\hline Монацит & - & $\begin{array}{l}9,2 \\
2,6\end{array}$ & 10,0 & 11,0 & $\begin{array}{l}+ \\
+\end{array}$ & 19,4 & $\begin{array}{l}9,8 \\
11,2\end{array}$ & $\stackrel{53,2}{-}$ & $\begin{array}{r}82,2 \\
1,4\end{array}$ & 5,3 & 0,7 \\
\hline Апатит & 4,7 & 4,1 & 1,0 & 13,6 & 4,9 & 12,8 & 2,8 & 20,8 & 10,4 & 26,6 & 50,8 \\
\hline Корунд & $\overline{0}$ & 0,8 & 1,4 & 0,6 & + & - & 4,9 & - & 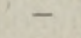 & 0,3 & t \\
\hline Рутил & 0,9 & 0,7 & 0,2 & - & 2,3 & - & 13,3 & - & - & & - \\
\hline Сфен & 4,2 & 1,0 & 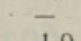 & 0,6 & 0,1 & - & 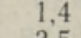 & 4,9 & - & 66,2 & - \\
\hline Анатаз & - & - & 1,9 & - & - & - & 3,5 & - & - & 0,1 & 0,2 \\
\hline 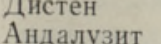 & $\overline{-}$ & $\overline{-}$ & $\overline{0,1}$ & - & + & - & - & 2 & $\bar{z}$ & $\overline{-}$ & $\overline{-}$ \\
\hline Ставролит & - & - & , & - & - & 3,2 & - & 0,5 & - & & - \\
\hline Эпидот & - & 6,7 & 15,0 & 3,5 & $0 \dddot{2}$ & 19,4 & 9,1 & 0,3 & - & 0,3 & - \\
\hline Флуорит & - & - & & - & & & & 2,0 & - & & 9,3 \\
\hline & 100 & 100 & 100 & 100 & 100 & 100 & 100 & 100 & 100 & 100 & 100 \\
\hline
\end{tabular}

+ - содержание минерала меньше $0,1 \%$.

ротин, является максимальным в богатых глиноземом гнейсах. В ряду от высокоглиноземистых до кварц-полевошпатовых гнейсов их содержание постепенно уменьшается по мере уменьшения глиноземистости и повышения кальциевости пород. Следует отметить, что ввиду высокого содержания рудных минералов в глиноземистых и графитовых гнейсах некоторые редкие акцессорные минералы могут остаться необнаруженными, т, е, замаскированными при анализе. 
Кроме рудных, сквозными (общераспространенными) минералами, встречаемыми во всех комплексах и типах пород, являются циркон и апатит. В распределении первого из них не отмечается особой закономерности, можно лишь приблизительно зафиксировать его высокое содержание в кварц-полевошпатовых гнейсах, обладающих наиболее кислым составом среди изучаемых пород (близких к гранито-гнейсам), и низкое в богатых кальцием породах (биотит-амфиболовые гнейсы). Апатит же имеет наиболее высокие содержания именно в биотит-амфиболовых гнейсах, особенно в предполагаемых парагнейсах мяэтагузеской пачки.

Важную петрогенетическую информацию несет в себе, по-видимому, распределение другого фосфата - монацита. Он присутствует во всех типах пород (кроме амфиболсодержащих) алутагузеской толщи и не встречается в породах ягалаской толщи. Можно предположить, что. кристаллизация монацита связана с геохимической спецификой первичного состава метаморфических пород алутагузеской толщи.

В изученных породах дифференцировано также распределение сфена. В литературе имеются противоречивые данные о содержании сфена в пара- и ортопородах. Многие авторы считают, что высокое содержание акцессорного сфена свойственно парапородам (Сидоренко, Ляхович, 1983; Кременецкий, 1979; Дусматов и др., 1982). В то же время В. В. Ляхович (1979), высказывает мнение, что ортогнейсы наряду с другими минералами содержат больше сфена. Нами установлено, что сфен. характерен для пород ягалаской толщи, особенно для кварцполевошпатовых и биотит-амфиболовых гнейсов. По геологическим и петрохимическим данным биотит-амфиболовые гнейсы ягалаской толщи определяются как первично-вулканогенные: в разрезах они чередуются с лептитами (кварц-полевошпатовыми гнейсами) и гранитами, по петрохимическим характеристикам (Неелов, 1980; Кременецкий, 1979; Simonen, 1953) они тяготеют к базальтам или габброндам. Биотитамфиболовые гнейсы алутагузеской толщи, в которых сфен отсутствует (но наблюдаются апатит и флуорит), встречаются только маломощными прослоями среди глиноземистых и биотитовых парагнейсов и петрохимически определены как первичноосадочные породы (карбонатные алевролиты или аргиллиты).

Таким образом, кажется правдоподобным, что в данном случае высокое содержание сфена связано с метаморфическими ортопородами (биотит-амфиболовые гнейсы ягалаской толщи), а низкое - с парапородами (алутагузеская толща). Естественно, такой вывод требует дополнительного контроля с использованием большого числа геологически и петрохимически надежно изученных проб.

С точки зрения оценки условий метаморфизма пород особый интерес представляет обнаружение дистена, андалузита и ставролита. Следует отметить, что пространственное распределение этих минералов хорошо согласуется с площадной схемой регионального метаморфизма в Северной Эстонии (Клейн, Пуура, 1986). Для пород ульястеской пачки установлена температура $(T)$ метаморфизма выше $700^{\circ} \mathrm{C}$ и давление $(P)$ 5-6 кбар. Появление в породе акцессорного дистена при таких условиях не только возможно, но даже вполне закономерно, подтверждающее правильность $T$-P-определений. Нахождение андалузита и ставролита в более низкотемпературных зонах также согласуется с соответствующими расчетными параметрами $T-P$-условий. Присутствие андалузита в относительно высоко метаморфизованных глиноземистых породах ульястеской пачки, видимо, указывает на возможные регрессивные изменения, упомянутые и ранее (Кристаллический..., 1983).

Акцессорным минералом, указывающим, видимо, на вторичные изме- 
нения в метаморфических породах, можно считать эпидот. Он встречается чаще в глиноземистых и биотитовых гнейсах алутагузеской толщи, реже - в породах ягалаской толщи.

Одним из важнейших генетических признаков акцессорных минералов является их морфология. Нами изучена только морфология циркона из глиноземистых, биотитовых и биотит-амфиболовых гнейсов (Конса, 1986). Циркон из глиноземистых и биотитовых гнейсов в подавляющем большинстве случаев представлен в различной степени окатанными зернами, надежно подтверждающими осадочную природу данных метаморфитов. Гнейсы алутагузеской толщи (в основном ульястеской пачки) содержат две генерации циркона: 1) обломочный - полуокругленный или округленный, содержит много включений, имеет иногда внутреннюю зональность; 2) метаморфогенный - панидиоморфный короткопризматический, имеет хорошо образованные кристаллы, прозрачные или полупрозрачные, иногда мутные, корродированные. Самостоятельные зерна второго типа встречаются крайне редко, обычно они образуют оболочки на зернах первой генерации.

В биотит-амфиболовых гнейсах алутагузеской толщи циркона очень мало, поэтому он изучен только в породах этой группы из ягалаской толщи. Здесь он в основном пан- или субидиоморфный, реже встречаются ясно идиоморфные кристаллы, часто имеет трещиноватость и включения, удлинение кристаллов в основном 3:1. Такая морфология циркона хорошо согласуется с отнесением этих пород к ортогнейсам.

С помощью полуколичественного спектрального анализа изучен м икрокомпонентный соста в магнетита и пирротина. Магнетиты пород алутагузеской толщи в целом богаче микрокомпонентами, содержание $\mathrm{V}, \mathrm{Ni}$ и $\mathrm{Cu}$ в магнетитах ягалаской толщи примерно в $2-3$ раза ниже (Клейн и др., 1984). Интересно отметить, что в пирротинах глиноземистых и биотитовых гнейсов алутагузеской толщи $\mathrm{V}, \mathrm{Ni}$, $\mathrm{Cu}$ и Со содержатся в повышенном количестве по сравнению с пирротинами ягалаской толщи. Если сравнить состав пирротинов графитовых и безграфитовых глиноземистых гнейсов, выясняется, что содержание $\mathrm{V}, \mathrm{Ni}, \mathrm{Cu}, \mathrm{Co}$ выше именно в пирротинах из безграфитовых ассоциаций. Так, низкое содержание микрокомпонентов в пирротине графитсодержащих пород алутагузеской толщи, и особенно ульястеской пачки, считавшихся потенциально рудоносными (Вахер и др., 1964; Пуура и др., 1976; Геохимическая..., 1978), пока не находит удовлетворительного объяснения и вопрос этот, видимо, разрешат более детальные исследования состава как рудных, так и породообразующих минералов.

Таким образом, выявленные различия видового состава и содержания акцессориев в однотипных породах разных структурных зон, а также особенности морфологии и микрокомпонентного состава вызывают серьезный интерес к дальнейшему изучению акцессорных минералов метаморфических пород. Все больший интерес представляют связи между распределением, морфологией и составом акцессорных минералов и генетическими особенностями вмещающих пород.

\section{ЛИТЕРАТ У РА}

Вахер Р. М., Кууспалу Т. И., Пуура В. А., Эрисалу Э. К. О геологическом положении сульфидных рудопроявлений в районе Ульясте. - В кн.: Литология палеозойских отложений Эстонин. Таллин, 1964, 33-53.

Bийдинг Х. Об. интерпретация данных минералогического анализа. - В сб.: Методика и интерпретащия результатов минералогических и геохимических исследований. Вильнюс, 1976, 53-59.

Геохимическая специализация магматических и метаморфических комплексов докем6. рия Белоруссии и Прибалтикн. Мннск, 1978. 
Геренчук Н. К., Янчук Э. Я., Лашманов В. Н., Галайко Х. Е. Акцессорные минералы глиноземистых пород некоторых доқембрийских формаций Украинского дщита. - Минерал. сб. Львов. ун-т, 1983, № 37/1, 47-53.

Дусматов В. Д., Акрамов М. 'Б., Верхотуров В. Е. Акцессорные минералы пара- и ортоамфиболитов восточной части Центрального Памира. - Докл. АН ТаджССР, 1982, 25, № 11, 680-683.

Клейн В. М., Пуура В. А. Изменения состава и генетические особенности метаморфических пород свекофеннского пояса (фундамент Северной Эстонии). - В сб.: Вещественный состав и происхождение горных пород докембрия Белоруссии и Прибалтики. Минск, 1986, (в печати).

Клейн B., Пуура В., Крылова М., Орловская К. Особенности распределения микрокомпонентов в магнетитах пород кристаллического фундамента Эстонии. Изв. АН ЭССР. Геол., 1984, 33, № 1, 37-45.

Конса М. Типоморфные особенности циркона пород кристаллического фундамента Эстонии. - Изв. АН ЭССР. Геол., 1986, 35, № 1, 1-9.

Конса М. И., Вийдинг X. А. Проблема унаследованности терригенных отложений (на примере сравнительного изучения коры выветривання кристаллического фундамента и базальных осадочных пород). - В кн.: Терригенные минералы осадочных пород Прибалтики. Таллин, 1983, 41-48.

Кременецкий $A$. А. Метаморфизм основных пород докембрия и генезис амфиболитов. M., 1979.

Кристаллический фундамент Эстонии. М., 1983.

Ляхович В. В. Акцессорные минералы горных пород. М., 1979.

Неелов А. Н. Петрохимическая классификация метаморфизованных осадочных и вулканогенных пород. Л.. 1980 .

Пуура В. А., Кивисилла Я. Я., Петерселль В. Х. Формации метаморфизованных осадочно-вулканогенных образований Северной Эстонии и их рудная минерализация. - В кн.: Геология, петрология и металлогения кристаллических образований Восточно-Европейской платформы. I. М., 1976, 169-176.

Сидоренко A. B., Ляхович B. B. Минералогия пара- и ортопород докембрия. - Изв. АН СССР. Сер. геол., 1983, № 6, 10-28.

Сидоренко А. В., Ляхович В. В. О генетическом значении акщессорных минералов. Минерал. журн., 1982,4 , № 6, 19-31.

Simonen, A. Stratigraphy and sedimentation of the svecofennidic, early archean supracrystal rocks in southwestern Finland. - Bull. Comm. Geol. Finl., 1953, № 160.
Ннститут геологии
Академии наук Эстонской ССР
Поступила в редакцию $7 / 11985$

\section{KLEIN, Mare KONSA}

\section{AKTSESSOORSETE MINERAALIDE JAOTUMINE POHJA-EESTI ALAMPROTEROSOIKUMI METAMORFSETES KOMPLEKSIDES}

Esmakordselt on antud ülevaade 17 aktsessoorse mineraali levikust ja jaotumisest Põhja-Eesti alamproterosoikumi metamorfiitides. Mineraloogilise analüüsi tulemused viitavad selgetele erinevustele aktsessoorsete mineraalide jaotumises eri struktuursete vööndite sama tüüpi kivimites. Tähelepanu on juhitud ka mōnede aktsessooride morfoloogia (tsirkoon) ning mikrokomponentse koostise (magnetiit, pürrotiin) iseärasustele.

\section{KLEIN, Mare KONSA}

\section{DISTRIBUTION OF ACCESSORIAL MINERALS IN THE NORTH-ESTONIAN LOWER PROTEROZOIC METAMORPHIC COMPLEXES}

A review of the distribution and arrangement of 17 accessorial minerals in the NorthEstonian Lower Proterozoic metamorphites has been given for the first time. The results of mineralogical analysis indicate distinct differences in the distribution of accessorial minerals in the rocks of the same type in different structural zones. Attention has been drawn to some peculiarities in the morphology of -the accessories (zircon) and in their microcomponential composition (magnetite, pyrrhotine). 